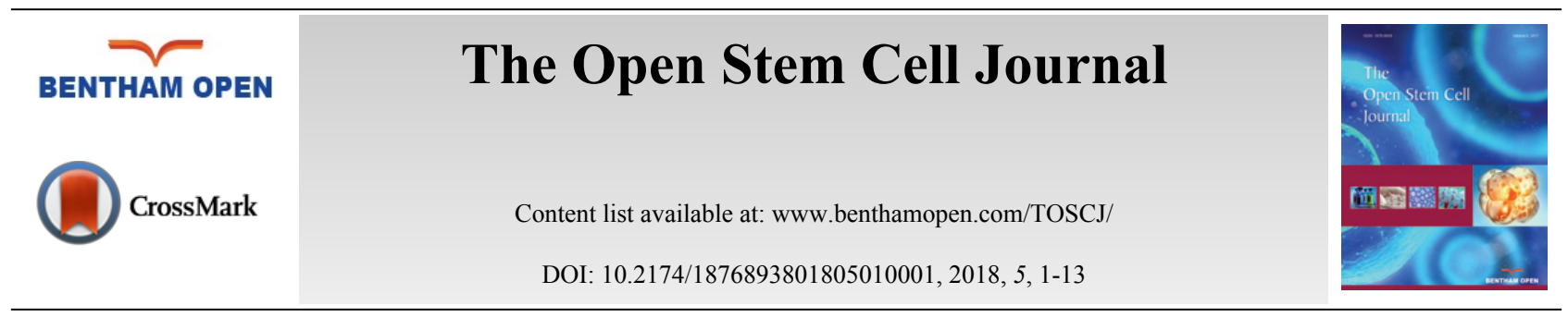

RESEARCH ARTICLE

\title{
Isolation, Culture and Characterization of Cancer Stem Cells from Primary Osteosarcoma
}

Achmad Fauzi Kamal ${ }^{1,2,}$, Deded Yudha Pranatha ${ }^{1}$, Waluyo Sugito ${ }^{1}$, Faisal Rahman ${ }^{1}$, Eka Susanto ${ }^{3}$, Silmi Mariya ${ }^{4}$ and Wei Ming Chen ${ }^{5}$

${ }^{I}$ Department of Orthopaedic \& Traumatology, Cipto Mangunkusumo General Hospital, Faculty of Medicine Universitas Indonesia, Jakarta, Indonesia

${ }^{2}$ Stem Cell Integrated Medical Technology Unit, Cipto Mangunkusumo General Hospital, Jakarta, Indonesia

${ }^{3}$ Department of Anatomic Pathology, Cipto Mangunkusumo General Hospital, Faculty of Medicine Universitas Indonesia, Jakarta, Indonesia

${ }^{4}$ Primate Research Center, Bogor Agricultural Institute, Bogor, Indonesia

${ }^{5}$ Department of Orthopaedic Surgery, Taipei Veterans General Hospital, Taipei, Taiwan

Received: May 15, 2018

Revised: August 26, 2018

Accepted: September 10, 2018

\section{Abstract:}

Background:

Osteosarcoma cancer stem cells (CSCs) are defined as a subpopulation of osteosarcoma cells, which have the ability of self-renewal, proliferation and differentiation. This study aimed to identify CSCs from human osteosarcoma in vitro .

\section{Methods:}

Osteosarcoma CSCs were isolated and cultured with sphere-forming assay technique on an ultra-low well attachment surface plate. After sarcosphere colonies were formed, we conducted reverse transcriptase-polymerase chain reaction (RT-PCR) to detect the expression of genes of embryonic stem cells such as NANOG, Oct3/4, STAT3 and gene of MSC CD133. Immunofluorescence analysis (IFA) of alkaline phosphatase (ALP), osteocalcin, and CD 133 was also performed to see the expression of osteosarcoma CSC surface protein with immuno-enzymatic staining principle. We also performed alizarin red staining to evaluate calcification in osteosarcoma CSCs.

\section{Results:}

The culture sphere-of the osteosarcoma cells showed three dimension round shaped colonies (sarcospheres) in slightly hypoxicand serum free condition which was not attached to the substrate with tight density. RT-PCR demonstrated that sarcospheres expressed genes which encode $N A N O G$, Oct3/4 STAT 3, but not for CD 133. IFA showed positive protein expression of ALP, osteocalcin and CD 133 which was moderate, strong, and weak positive respectively. Sarcospheres also had a positive reaction toward alizarin red staining.

\section{Conclusion:}

Osteosarcoma CSCs could be isolated from human osteosarcoma by sphere-forming assay technique and characterized by the expression of genes of embryonic stem cells, such as NANOG, Oct3/4, STAT3 and IFA of ALP, osteocalcin, and CD 133.

Keywords: Osteosarcoma, Cancer stem cells, Sarcosphere, CD133, NANOG, Alkaline phosphate.

\footnotetext{
* Address correspondence to this author at the Department of Orthopaedic \& Traumatology, Cipto Mangunkusumo General Hospital, Faculty of Medicine Universitas Indonesia, Jakarta, Indonesia; Tel: (+62) 1511450189; E-mail: fauzikamal@yahoo.com
} 


\section{INTRODUCTION}

Osteosarcoma is a primary malignant bone tumor, commonly found in children and adolescents, which represents almost $60 \%$ of all bone sarcomas. It is an osteoid-matrix-producing solid tumor and mostly develops in long bones, usually on metaphysis close to epiphyseal growth plate [1 - 3].

The incidence of osteosarcoma in all populations is around 4-5 per 1 million people. Incidence estimation of osteosarcoma increases to 8-11 per one million individuals per year at the age of 15-19 years. Osteosarcoma is known to have a bimodal age distribution with first peaked in young adults and the second in the elderly [2, 4 - 7]. Within a period of 13 years (1995-2007), there were 219 cases (16.8/year) at Cipto Mangunkusumo General Hospital, Jakarta with the largest distribution in the second decade [8].

The outcome for a patient with osteosarcoma has improved significantly from $25 \%$ to $60 \%$ as a result of administration of systemic chemotherapy and the development of surgical techniques [1 - 3]. The multi-disciplinary therapy has resulted in disease-free survival of $60-80 \%$ while allowing the use of functional limb salvage surgery in $>80 \%$ of patients [4]. However, 20 to $40 \%$ of patients ultimately die of osteosarcoma because of pulmonary metastases $[2,9]$. Unfortunately, micrometastases are often already present at the time of diagnosis [10].

The management of metastatic osteosarcoma is very difficult and current surgical intervention still does not guarantee life viability [11 - 14].One of the major causes failure of the cancer cells to respond to the chemotherapeutic agents administered is drug resistance [9]. Chemotherapeutic agents often fail to completely eliminate cancer stem cells (CSCs), which are able to repopulate the tumor mass, causing relapse and distant metastases. Thus, CSCs represent a pivotal pharmacological target to obtain effective therapeutic responses in cancer $[15,16]$.

Osteosarcomas are characterized by intratumor cell heterogeneity that could be explained by the recent CSC hypothesis. According to this theory, a subpopulation of cancer cells with stem-like properties, therefore named CSCs, is present within the hierarchical tumor organization. CSCs can divide asymmetrically, producing an identical daughter cell and have a pluripotent characteristic with self-renewing and the ability to differentiate into various cell types with high survival rates [17 - 20]. CSCs are derived from stem cells or progenitor cells that underwent dysregulation in proliferation and differentiation [21].They are responsible for tumor development and recurrence, and drug resistance to chemotherapeutics [22 - 24].

Gibbs et al., reported the existence of CSCs in osteosarcoma [24]. They demonstrated that human osteosarcoma had a small number population of cancer cells that might grow in a clonal cluster environment when placed in a solution of serum-free conditions. The cell cluster is now referred to as sarcosphere or osteosphere [24].

A number of cell lines have successfully been cultivated and characterized from human [25 - 28] and canine [29, 30] osteosarcomas. A large number of human osteosarcoma cell lines are commercially available, like HOS [31], U2 OS [32], Saos-2 [33], or MG-63 [34]. CSCs of human osteosarcomas, in Indonesia, have rarely been studied, and to our knowledge, this work presents the first establishment and description of a human osteosarcoma cell line from primary human osteosarcoma.

In this study, cancer stem-like cells have been isolated from human osteosarcoma primary cultures and biomolecular characterization of these cells has been performed such as NANOG, Oct3/4, and STAT3), and CD133. The cultivated osteosarcoma cells were also tested for bone tumor markers as such as tissue unspecific alkaline phosphatase, osteocalcin, and alizarin red staining.

\section{MATERIALS AND METHODS}

\subsection{Isolation and Culture of Human Osteosarcoma Cells}

Primary tissue samples were taken from osteosarcoma patients who underwent open surgical biopsy or amputation. Each tissue sample was divided into two parts, one part for cell culture and one part for histopathologic examination. Tissue samples that were not intended for histopathologic examination were placed in sterile tubes containing DMEM with2\% antibiotic (Dulbecco's Modified Eagle Medium; Gibco ${ }^{\circledR}$, Life Technologies, InvitrogenTM, Carslbad, CA, USA) and then sent to culture laboratory immediately.

We cut the surgical samples into $2-4 \mathrm{~mm}$ square sections and washed with sterile phosphate buffered saline (PBS, Life Technologies Inc., USA). Tumor cells were released from the samples by enzymatic treatment with $0.1 \%$ 
collagenase (Sigma Aldrich, Irvine, UK). Samples were agitated 20 minutes. At the end of incubation, samples were centrifugated at $700 \mathrm{xg}$ for 10 minutes. The supernatants were discarded and $0.25 \%$ trypsin (Invitrogen USA) were added and incubated for 10 minutes to reach single cells.

Cells suspension were homogenized and filtrated using strainer 70 micrometer then $10 \mathrm{~mL}$ of DMEM and penicillin-streptomycin 1\% (Gibco ${ }^{\circledR}$, Life Technologies, InvitrogenTM, Carslbad, CA, USA) were added. The suspension was washed by centrifugation at $700 \mathrm{x}$ gfor 10 minutes. Cell population was counted with a hemocytometer.

Cells suspension was centrifuged again at $700 \mathrm{x} g$ for 10 minutes. Growth medium DMEM with $\mathrm{NaHCO}_{3}\left(\mathrm{Gibco}^{\circledR}\right.$, Life Technologies, InvitrogenTM, Carslbad, CA, USA), 10\% FBS and PS 1\% was added. Cells were cultured in $37^{\circ} \mathrm{Cwith} 5 \% \mathrm{CO}_{2}$ and $95 \%$ air. The growth medium was replaced every 3-4 days. When the cells had reached $80 \%$ confluence, subculture was done by removing the cells from its substrate using $0.25 \%$ Trypsin - EDTA (Invitrogen,USA).

\subsection{The Subculture of Osteosarcoma Cell}

Cells were subcultured when the population reached $\sim 80 \%$ confluence, the growth medium was removed, then monolayer cells adhered to the plate were rinsed with $5 \mathrm{~mL}$ PBS. $1 \mathrm{~mL}$ of $0.125 \%$ trypsin (Invitrogen,USA) was added to the plate and incubated at $37^{\circ} \mathrm{C}, 5 \% \mathrm{CO}_{2}$ and $95 \%$ air for 5 minutes. $1 \mathrm{~mL}$ growth medium was added to deactivate trypsin. The cells and medium were put into a $15 \mathrm{~mL}$ polypropylene tube and centrifuged at $400 \mathrm{x} g$ for 5 minutes. The supernatant was removed, the cells were re-suspended with $10 \mathrm{~mL}$ DMEM. Subsequently, the cells were counted with a hemocytometer and were grown in TC flask 25 and incubated at $37^{\circ} \mathrm{C}, 5 \% \mathrm{CO}_{2}$ and $95 \%$ air.

\subsection{Phenotypical Analysis: Morphological, Cytological and Immunocytochemistry Examination}

Morphological examination of cells on a plate containing culture media was evaluated by using an inverted microscope and through cytology examination with standard Papanicolaou staining. Under light microscope Leica ICC50 HD®. Immunocytochemistry examination of cultured cells of alkaline phosphatase (ALP) and osteocalcin was conducted by immuno-enzymatic staining principle. The slide was rehydrated with graded alcohol (absolute, $96 \%$ and $80 \%$ ) every 4 minutes, blocked with $0.5 \% \mathrm{H}_{2} \mathrm{O}_{2}$ in methanol for 30 minutes and then washed in water for 5 minutes. Pretreatment of the slide was performed with citrate buffer in microwave Cook I and Cook II in 5 minutes, followed by blocking background target to block non-specific antigens and then incubated for 15 minutes. Then it was given primary antibody ALP / osteocalcin and incubated for 1 hour. The slide was given a universal ink secondary antibody to bind to the primary antibody for 15 minutes. After that, counterstaining was performed with haematoxylin for 1-2 minutes.

\subsection{Isolation and Culture of Osteosarcoma CSCs: Sphere Forming Assay}

The pleomorphic spindle cells (that were successfully isolated and cultured from primary osteosarcoma) were grown on 6 wells of ultra-low attachment surface tissue culture plate (Corning Inc, Corning, NY) with concentration of $1 \times 10^{5}$ cells per well in DMEM that had been supplemented with FBS $10 \%$ and PS1\% (Gibco ${ }^{\circledR}$, Life Technologies, InvitrogenTM, Carslbad, CA, USA). Culture plate was covered with parafilmon the first three days and incubated at $37^{\circ} \mathrm{C}, 5 \% \mathrm{CO}_{2}$ and $95 \%$ air. On day three, parafilm (3M, USA) was opened and the growth medium was replaced. Subsequently, the cells were put-in polypropylene $15 \mathrm{~mL}$ tube and underwent re-suspension with $4 \mathrm{~mL}$ medium.Centrifugation was performed at 500x $g$ for 5 minutes (Beckman,Germany). The supernatant was removed, the cells were re-suspended with $1 \mathrm{~mL}$ medium and incubated at $37^{\circ} \mathrm{C}, 5 \% \mathrm{CO}_{2}$ and $95 \%$ air (Thermo Forma Scientific, USA).

\subsection{Sarcosphere Subculture}

After the colonies were counted, the cells were put into a $15 \mathrm{~mL}$ polypropylene tube, centrifugation was conducted at 500x $\mathrm{g}$ for 5 minutes. The supernatant was removed and $3 \mathrm{~mL} 0.25 \%$ trypsin was added into the tube and incubated at $37^{\circ} \mathrm{C}, 5 \% \mathrm{CO}_{2}$ and $95 \%$ air for 5 minutes. Centrifugation was re-performed at $500 \mathrm{x} g$ for 5 minutes. Supernatant was removed, the cells were re-suspended with $2 \mathrm{~mL}$ medium. Cells were counted with a hemocytometer and were grown in ultra-low well attachment surface tissue culture plate with concentration $1 \times 10^{4}$ cells $/ \mathrm{mL}$, covered with parafilm and incubated at $37^{\circ} \mathrm{C}, 5 \% \mathrm{CO}_{2}$ and $95 \%$ air. 


\subsection{Characterization of Osteosarcoma CSCs}

Characterization of osteosarcoma CSCs was conducted with reverse transcriptase-polymerase chain reaction (RTPCR) and immunofluorescence analysis (IFA). RT-PCR was used to detect the expression of pluripotent biomarkers such as NANOG, Oct3/4, STAT3 and mesenchymal stem cell such as CD133. IFA of ALP, osteocalcin, and CD 133 was also performed to see the expression of osteosarcoma CSC surface protein with immuno-enzymatic staining principle. Alizarin red staining was conducted to prove the calcification of sarcosperes.

\subsection{Reverse Transcription Polymerase Chain Reaction (RT-PCR)}

mRNA extraction using the RNeasy kit (Qiagen, USA) and RT-PCRusing the Super Script®III ReverseTranscriptase kit (Invitrogen, USA) were done according to the standard procedure of the company. PCR amplification stages consist of denaturation at $94^{\circ} \mathrm{C}$ for 30 seconds, annealing (NANOG, Oct3/4, STAT3 and CD133 and GAPDH) at $54^{\circ} \mathrm{C}$ temperature for 30 seconds and elongation at $72^{\circ} \mathrm{C}$ for 30 seconds, repeated for 40 cycles. Sequence primer could beseen in Table 1. PCR results were passed into a $2 \%$ agarose gel that contained Ethidium Bromide in Tris-acetat-EDTA buffer solution (Gibco,USA). Electrophoresis was performed in 100 volts for 45 minutes and its visualization was documented by using Gel Doc (Biorad,USA).

Table 1. Primary sequneces pairs used in RT-PCR.

\begin{tabular}{|c|c|c|c|}
\hline Gene & Forward Primer & Reverse Primer & Product (bp) \\
\hline Nanog & GCTGAGATGCCTCACACGGAG & TCTGTTTCTTGACTGGGACCTTGTC & 163 \\
\hline Oct 3/4 & TGGAGAAGGAGAAGCTGGAGCAAAA & GGCAGATGGTCGTTTGGCTGAATA & 186 \\
\hline STAT 3 & GGGTGGAGAAGGACATCAGCGGTAA & GCCGACAATACTTTCCGAATGC & 198 \\
\hline CD 133 & AAGCATTGGCATCTTCTATGG & AAGCACAGAGGGTCATTGAGA & 233 \\
\hline
\end{tabular}

\subsection{Immunofluororescence Analysis (IFA)}

Sarcospheres were were grown in 8-well tissue culture plate (CorningInc, Corning, NY). The cells were fixed in methanol for 2 minutes, then in acetone for an additional 2 minutes. Slides were rinsed three times using PBS (Invitrogen, USA). Following fixation, Primary antibodies for alkaline phosphatase (EPR4477) ab 108337 (Abcam, USA), osteocalcin (OC4-30) ab 13418 (Abcam, USA), CD 133/1 (AC 133) (MACS, Germany) were added to slides and incubated at $37 \mathrm{C}$ temperature for 60 minutes. Slides were rinsed three times with PBS and secondary antibodies which had been labeled by FITC were added. Incubation was performed at 37C temperature for 60 minutes. Evans Blue (Sigma, USA) staining was added to the slides and incubated at room temperature for 2 minutes. Slides were rinsed in PBS (Invitrogen, USA) viewed under a fluorescence microscope at 20x and 40x magnification (Nikon, Japan).

\subsection{Alizarin Red Staining}

Sarcospheres were cultured in tissue culture plate 12 wells (ComingInc, Corning, NY) for 7 days. After the growth medium was removed, each well was rinsed three times with PBS for 5 minutes. $10 \%$ of Formaldehyde was added to each well for 10 minutes, then the well was rinsed again three times with PBS. Alizarin red 2\% was added into each well and incubated at $37^{\circ} \mathrm{C}$ for 15 minutes. Subsequently, each well was rinsed three times with PBS for 5 minutes and viewed with an inverted microscope (Nikon, Japan).

\section{RESULTS}

\subsection{Osteosarcoma cell Cultures}

Tissue samples were obtained from 2 osteosarcoma patients who had no neoadjuvant chemotherapy. Two primary human cell cultures were obtained from post-surgical tumor specimens with a histologically confirmed diagnosis of conventional osteosarcomas. Those cells showed a fibroblast-like morphology when grown as nucleated monolayer cells on plastic cell culture. On further observation, the cells underwent elongation with pleiomorphic shapes (Fig. 1).

The subculture of osteosarcoma cells was conducted after the cells reached $80 \%$ confluence. Passage P2 to P5 subculture was performed at day 7 but P1 waited for 10 days. We found that the total number of cells were increasing on each passage. This cell population has been successful to be subcultured up to the $5^{\text {th }}$ passage, and may represent increased apoptosis, decreased proliferation since these cells were not immortal cells. 


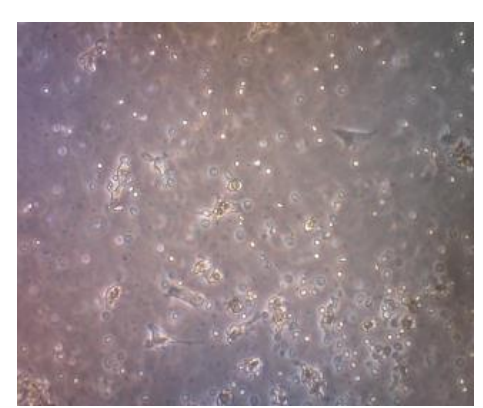

A

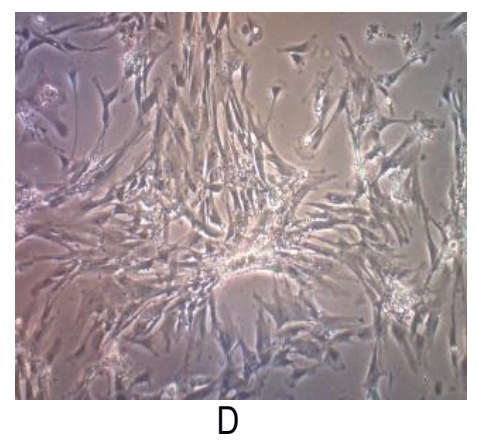

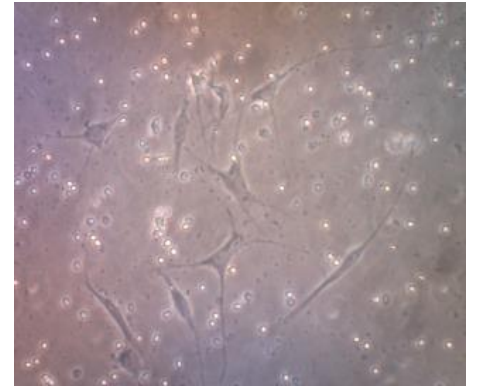

B

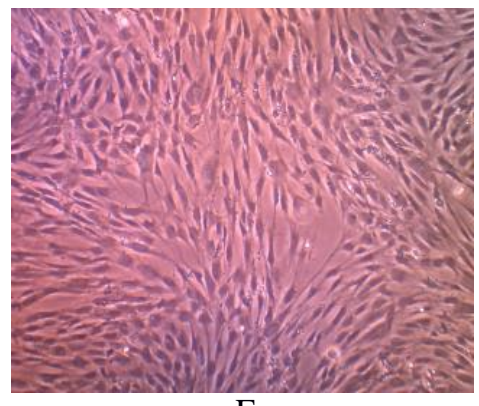

E

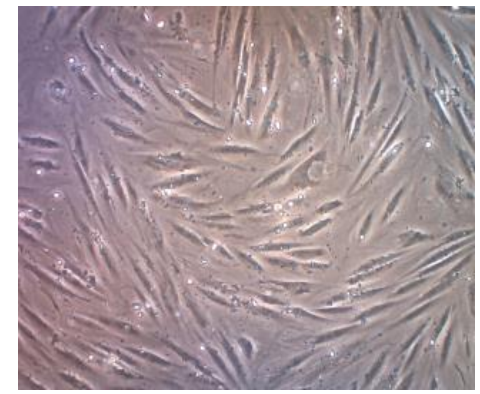

C

Fig. (1). Those showed the growth of cell colonies from isolated human osteosarcoma tissue. Spindle cells were attached to the culture plate surface (100x magnification). A). Cells on the culture media; B) and C). Some cells showed elongated appearance resemble fibroblast; D). The cells underwent elongation with pleiomorphic shapes; E). Those cells reached 80\% confluent (x100).

Cytology examination with Papanicolaou staining showed osteoblast-like cells with pleomorphic, hyperchromatic nuclei and prominent nucleoli (Fig. 2). Immunocytochemistry examination demonstrated positive for alkaline phosphatase and osteocalcin expression (Fig. 2).

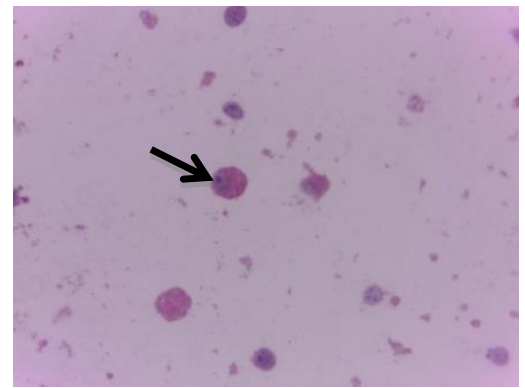

A

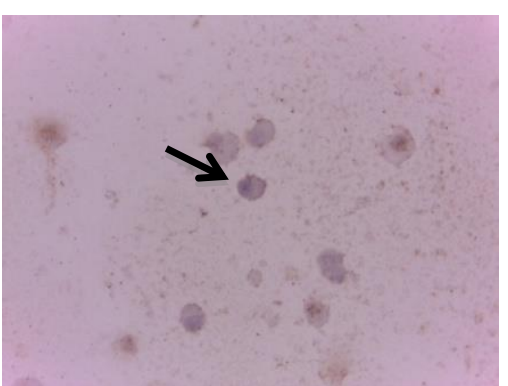

B

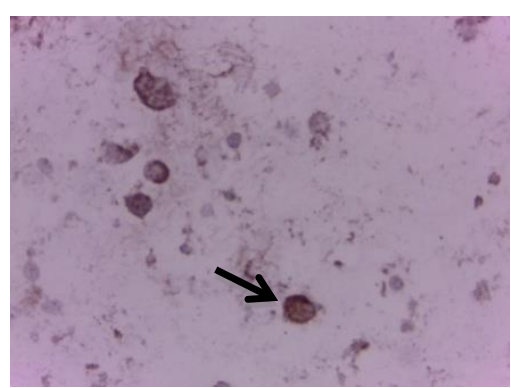

C

Fig. (2). Osteoblast like cells from osteosarcoma cell cultures with eccentrically located nuclei and prominant nucleoli. (A) (Papanicolaou, 400x). Immunocytochemistry examination demonstrated positive for alkaline phosphatase (B) and osteocalcin expression (C).

\subsection{The culture of osteosarcoma CSCs: Sphere formation assay}

We successfully isolated and cultured CSCs from human osteosarcoma cell cultures growing them in the stem cell serum free medium. These cells, representing a subset of human osteosarcoma cells possess stem cell-like features, retaining the ability to self-renew in vitro. Osteosarcoma stem-like cells showed three-dimensional sphere clusters (sarco-spheres) in slightly hypoxic condition in the first three days.Those osteosarcoma stem like-cells were not 
attached (non-adherent) to substrate with tight density. Sarcospheres were able to produce normal adherent cell cultures (Fig. 3).

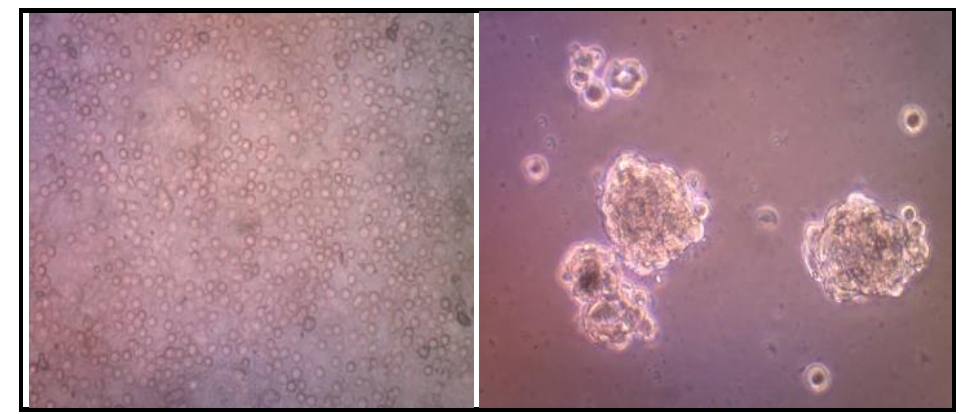

A

B

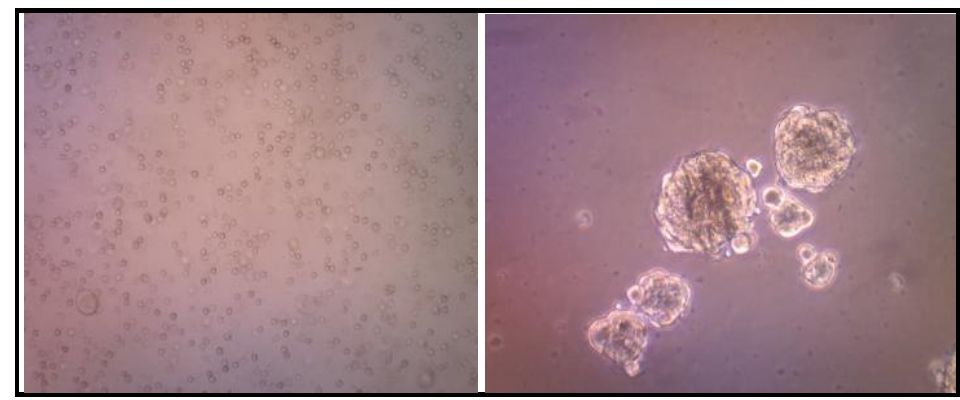

C

D

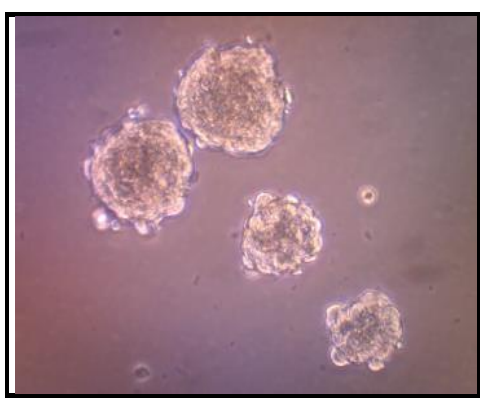

$\mathrm{E}$

Fig. (3). Human osteosarcoma cells isolated and cultured in non-adherent culture/ultra low attachment surface tissue culture plate (100x magnification). A). On day (D)1 all spherical cells were not attached to substrate with tight density within the serum-free and hypoxic medium; B). On D7 The cells formed sarcospheres and reached $\sim 80 \%$ confluence (P1); C). After sarcospheres transferred back into non-adherent culture plate, spherical cells were not attached to substrate again ; D) and E). Those cells reformed sarcospheres on D14 (P2) on D21 respectively.

Moreover, we observed that osteosarcoma stem-like cells, when transferred in the standard medium, are able to grow as adherent monolayers with the same characteristic of the corresponding osteosarcoma cell line of origin suggesting the retaining of ability to differentiate in non-stem cancer cells.

A characteristic property of CSCs is their unique ability to self-renew. One of the methods to determine this ability is to test CSC capability of serial passage in vitro, thus to more deeply investigate the self-renewing ability of osteosarcoma stem-like cells, sarcospheres were dissociated into single cells and re-seeded at increasing cell densities, which allowed for the formation of separate non-adherent three-dimensional sphere clusters, in serum free medium. The passages were repeated every 7-21 days, by monitoring sphere formation efficiency. On day 7 sarcospheres reached $\sim 80 \%$ confluence (Fig. $\mathbf{3 A}$ and $\mathbf{B}$ ). 
The osteosarcoma stem cells formed sarcospheres and were successful to be subcultured up to the $3^{\text {rd }}$ passage. On passage $15 \times 10^{5}$ cells were transferred back into ultra-low attachment surface tissue culture plates for each well with a total number of cells $2 \times 10^{6}$. On day 14, osteosarcoma stem-like cells formed sarcospheres with sphere formation efficiency being $0.030 \%$. On day 21 passage $2,2 \times 10^{5}$ those osteosarcoma stem-like cells formed sarcospheres with sphere formation efficiency as $0.03375 \%$. On passage 3 , those $9 \times 10^{4}$ cells were grown into ultra low attachment surface tissue culture plates and formed sarcospheres as well. However, termination of the sarcosphere forming process was considered (Figs. 3C-E).

\subsection{Characterization of osteosarcoma CSCs}

3.3.1 RT-PCR examination showed that the sarcospheres expressed genes which encode pluripotent biomarker NANOG, Oct3/4, STAT3 and of MSC CD 133 (Figs. 4A and 4B). The RT-PCR result was supported by IFA examination. It demonstrated positive of ALP, osteocalcin and CD 133 which was moderate, strong, and weak positive respectively (Fig. 5). Calcification of the tumor cell cultures was determined by alizarin red staining. Sarcospheres also showed positive reaction toward alizarin red staining (Fig. 6).

\section{Sarcosphere}
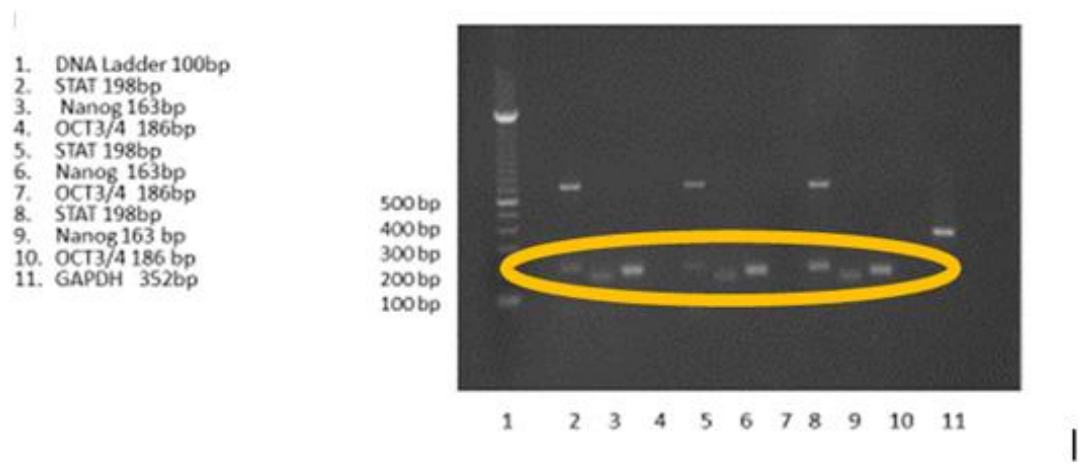

Fig. (4A). RT-PCR result of osteosarcoma CSCs. RT-PCR showed positive expression of puripotent biomarkers $N A N O G$, Oct3/4 and STAT 3. White band showed gene location targeted.

CD133

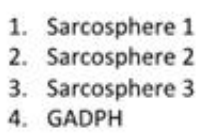

1. Sarcosphere 1

3. Sarcosphere 3

4. GADPH

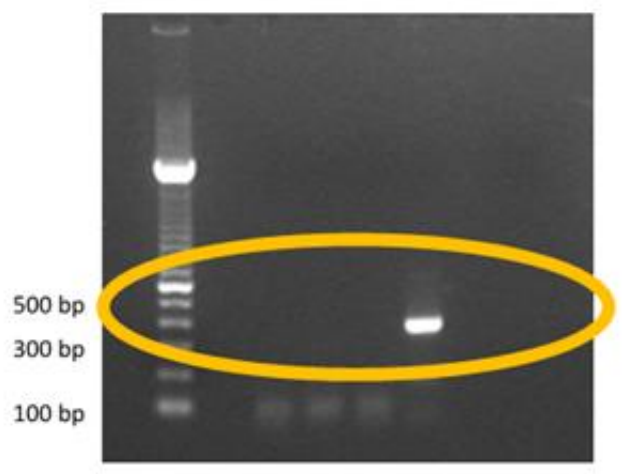

S1 S2 S3 GAPDH 352bp

Fig. (4B). Osteosarcoma CSCs RT-PCR result using CD 133. RT-PCR demonstrated no expressionof CD 133 marker. 


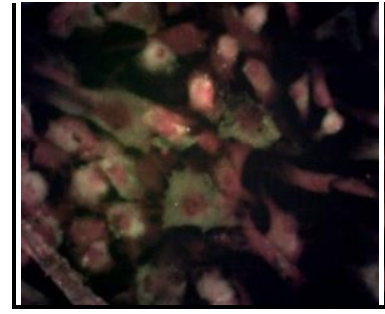

A

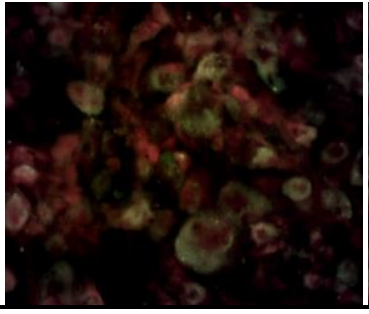

B

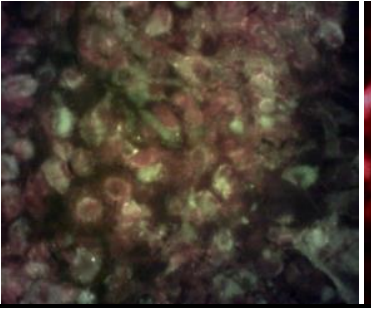

C

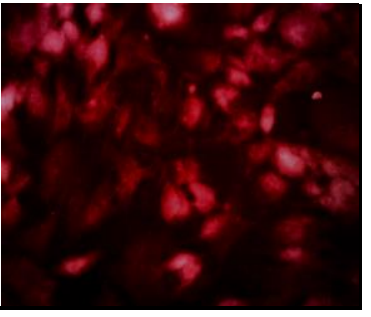

D

Fig. (5). Immunofluoroscence analysis of ALP, osteocalcin, and CD 133 was evaluated at 100x magnification. A). IFA of ALP showed moderate positive expression; B). IFA of CD133 demonstrated weak positive expression; and C). IFA of osteocalcin showed strong positive expression; (D) Negative control.

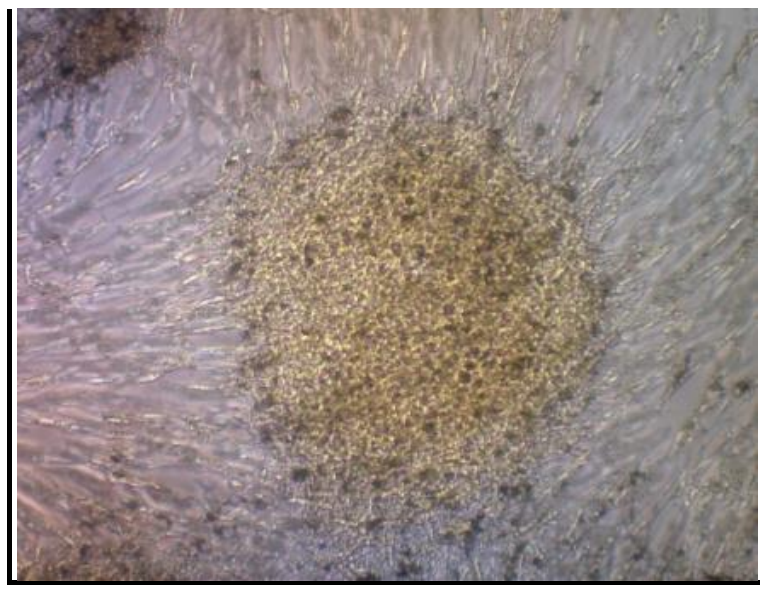

A

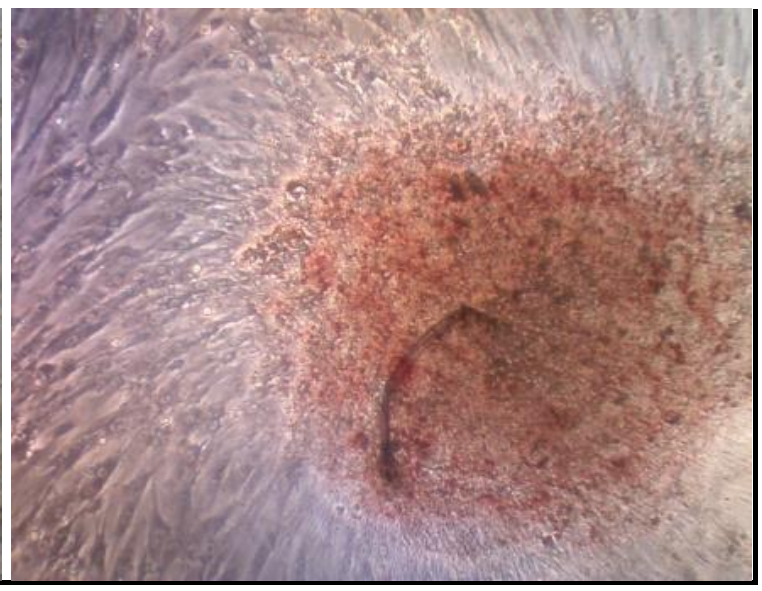

B

Fig. (6). We reveled that sarcospheres produced calcium in vitro. Alizarin red staining results on adherent culture plate. (A) On day 3; (B) On day 7. At 32x magnification.

\section{DISCUSSION}

Some literature stated that the culture of osteosarcoma cells, either from the primary cells as well as from a cell line, will show limited cancer cell population when grown in a serum-free on the non-adherent condition. Only primitive cells that have the ability to form sphere colonies that could survive [19, 35, 36]. Some researchers have managed to show that there are sarcoma cell group that have the capacity to form a sarcosphere in culture $[6,19,35,37]$.

A cell, which is regarded as a stem cell in a culture, should be able to demonstrate the capacity to proliferate, renew through a long period of time, and produce a large amount of derivatives that can differentiate into primary cells type [38]. A small amount of cells that have the stem cell ability will form a three-dimensional clonal patterns (spheres) in anoikis non-adherent cultured environment $[16,39]$. The stem like cells can be expanded in vitro and repeatedly form spheres after multiple passages in long-term assays [16]. When those cells are transferred back into adherent culture plate, they may attach to the plate surface [35].

Those findings are consistent with our present study. In the ultra-low well attachment surface tissue culture plate, the cells had the ability to form sarcosphere. They could re-attach to the plate surface when the sarcospheres transferred back to a tissue culture plate. The ability to self-renew, proliferate by forming spheres and reattach to the monolayer culture plate, proved that the obtained cells contained small amount populations of primitive cells that were suspected as CSCs [6]. 
Also, similar results were reported by Gibbs et al., [19] who identified CSCs osteosarcoma from osteosarcoma tissue samples and cell line MG-63 through the sphere-forming assay. Wilson et al., [35] also reported CSCs from isolation and culture of canine osteosarcoma cell lines. Wang et al. [36] successfully observed human osteosarcoma cell lines. Gibbs et al., Wilson et al. and Wang et al. demonstrated a small amount of population of cells which were capable to form a sarcosphere.

Pluripotent cells are characterized by the expression of a group of genes required to maintain the stem cell-like feature such as NANOG [40], Oct3/4 [41], and STAT3 [19], a transcription factor that regulates the suppression of differentiation genes [42], and although less evident CD133 as also described in canine osteosarcoma tissue biopsies [43]. Our study was consistent with those studies. RT-PCR demonstrated the positive expression of genes $N A N O G$, Oct3/4 and STAT3, but negative expression CD133. Also, a previous study by Gibbs et al., [19] reported the positive expression of $N A N O G$ and Oct3/4 on sarcospheres. Wilson et al., [35] also successfully proved the expression of NANOG, Oct3/4, and STAT3 in the adherent osteosarcoma culture and sarcosphere. Wang et al., [36] and Lou et al., [37] reported Oct3/4 expression in osteosarcoma and NANOG expression in cell line MG-63 M respectively.

Osteosarcoma development may be ascribed to altered osteogenic differentiation into mature osteoblast [16].In the present study, the sarcospheres demonstrated osteoblast activity. We revealed a subset of immunopositive cells which were consistent with the presence of markers of differentiation ALP and osteocalcin. It indicates an heterogeneous cell population not exclusively composed of completely mature cells but also by a more undifferentiated subpopulation.

A positive ALP also indicated the pluripotent trait was available on the sarcosphere. Singh et al., [44] and Pautke et al., [28] revealed positive expression of the ALP in human embryonic stem cells and in the osteosarcoma cell lines (MG-63, Saos-2 and U-2 OS) respectively. ALP activities were also found in canine osteosarcoma cell lines [27, 29,]. In human osteosarcoma cells, tissue unspecific ALP activity was dependent on cell density [28], therefore, this condition has to be considered when comparing data about ALP.

Osteocalcin, a small peptide hormone produced by osteoblasts, was used to verify the bony origin of our new cell lines. Osteocalcin was a protein marker of osteoblast that had been frequently used in MSCs studies [45, 46].The use of osteocalcin marker in osteosarcoma cells was identical to the osteosarcomagenesis process [5].

Some previous studies have reported the various expression of CD 133 in osteosarcoma CSCs. CD133 is a glycoprotein with 3 isoforms that have been widely used for isolating CSCs.Di Fiore et al., [47] reported strong expression of CD133 in AB-OS cell line but not in osteosarcoma cell line MG-63. While Lou et al., [37] found a strong expression of CD133 osteosarcoma cell line MG-63-M but only slightly visible on osteosarcoma cell line MG-63. Saini et al., [48] found astrong expression of CD133 in monolayer osteosarcoma cell lines (Saos-2, CHA59, HuO9)but weaker in the sphere Saos-2 and CHA59.Acohort study conducted by He et al., [49] mentioned that the positive expression of CD133 in osteosarcoma patient had clinical lung metastasis in $46(65,7 \%)$ of patients. In this study, CD133 could not be detected by RT-PCR and showed a weak positive by IFA. We evaluated that the amount of osteosarcoma CSCs was too small.This could be demonstrated by FACS analysis before the cells formed sphere, CD 133 could be multiplied before analysis or with a qPCR technique.

We revealed that sarcospheres produced calcium in vitro. Sarcosphere showed the bright orange-red color that indicated the occurrence of alizarin red complex bonded with calcium [41, 50]. Luk et al., [51] had reported the characterization of osteosarcoma cell lines Saos-2 and U-2 OS successfully. In the canine osteosarcoma, the sarcosphers also showed strong calcification after three days in culture, as demonstrated by alizarin red staining [50].

Osteoblast activities in osteosarcoma and osteogenic differentiated MSCs showed positive results on alizarin red staining [51].Osteoblasts may be induced to produce extracellular calcium deposits in large numbers in vitro. In this study, calcium deposits in sarcospheres showed bone formation in vitro and could be stained with alizarin red. Alizarin red will bind with calcium to form alizarin red calcium complexes [52].

Although the methods utilized to detect the osteosarcoma CSC show populations with enriched stem cell-like characteristics, no specific markers for the osteosarcoma CSC have been established. Understanding of the MSC may aid in successful specific isolation of the osteosarcoma CSCs. Therefore, further research is required to fully understand the biological functions of CSC markers in order to accurately isolate osteosarcoma CSC [53]. The isolation and identification of the small subpopulation of CSCs from sarcomas was a long-term conundrum that stagnated research with no substantial breakthrough. Currently, the methods of isolations can becategorized into three main types, including sarcospheres (tumorospheres), side population sorting, and sorting cells according to specific cell surface 
markers [54]. So far, the most useful and promising methods for selecting osteosarcoma stem cells are sarcospheres.

It is important to improve the methods of CSC isolation through the study of CSC biology, with the final goal of finding molecular targets and developing a very specific anticancer therapy directed against this particular cellular subset, which is probably responsible for the maintenance of the primary tumor, the development of its recurrence, and the origin of metastases in several organs. The study of CSC biology is also important to finding therapies that could be incisive in the cure of cancers, such as osteosarcoma, for which the survival rate after neo-adjuvant treatment remains very poor [53].

A host of different approaches are currently being explored to eliminate CSCs, ranging from small molecules that selectively inhibit key cell signalling pathways to immunological approaches, which can target multiple tumour antigens and potentially eliminating cancer cells through harnessing of innate immune responses.

\section{CONCLUSION}

Tissue stem cells have been identified through the ability of cells to form spheres and this method has also been used to assess CSC presence. CSCs could be isolated and cultured in vitro from human osteosarcoma with sphere forming assay technique. Sarcospheres showed three dimension round shaped colonies in slightly hypoxicand serum free condition which was not attached to the substrate with tight density. They expressed genes which encode of NANOG, Oct3/4, STAT 3 and had a positive protein expression of ALP, osteocalcin and CD 133, and also had a positive reaction toward alizarin red staining.

\section{ETHICS APPROVAL AND CONSENT TO PARTICIPATE}

This study was approved by the Health Research Ethic Committee Faculty of Medicine Universitas Indonesia- Cipto Mangunkusumo Hospital Reference no 752/UN2.F1/ETIK/2014.

\section{HUMAN AND ANIMAL RIGHTS}

No Animals were used in this research. All human research procedures followed were in accordance with the ethical standards of the committee responsible for human experimentation (institutional and national), and with the Helsinki Declaration of 1975, as revised in 2008.

\section{CONSENT FOR PUBLICATION}

Not applicable.

\section{CONFLICT OF INTERESTS}

The authors declare no conflict of interest, financial or otherwise.

\section{ACKNOWLEDGEMENTS}

Writing support was provided by Jessica Fiolin, MD.

\section{REFERENCES}

[1] Basu-Roy U, Basilico C, Mansukhani A. Perspectives on cancer stem cells in osteosarcoma. Cancer Lett 2013; 338(1): 158-67. [http://dx.doi.org/10.1016/j.canlet.2012.05.028] [PMID: 22659734]

[2] Salter RB. Neoplasms of musculoskeletal tissues.Textbook of disorder and injuries of musculoskeletal system. $3^{\text {rd }}$ ed. Philadelphia: Williams \& Wilkins 1999; pp. 379-414.

[3] Unni KK. Osteosarcoma.Dahlin's bone tumors 5. Philadelphia: Lippicott-Raven Publishers 1996; pp. 122-43.

[4] Raymond AK, Ayala AG, Knuutila S. Conventional osteosarcoma.Christopher M Fletcher CDM, Unni KK, Mertens F World Health Organization classification of tumors: pathology and genetics of tumours of soft tissue and bone. Lyon: IARC Press 2002; pp. 264-85.

[5] Tang N, Song WX, Luo J, Haydon RC, He TC. Osteosarcoma development and stem cell differentiation. Clin Orthop Relat Res 2008; 466(9): 2114-30. [http://dx.doi.org/10.1007/s11999-008-0335-z] [PMID: 18563507]

[6] Neves SI. Functional evaluation of cancer stem cells in osteosarcoma during differentiation and its implications in response to chemotherapy [thesis]. Coimbra, Portugal; University of Coimbra. 2011; 49.

[7] Bashur L, Zhou G. Cancer stem cell in osteosarcoma. Case Orthop J 2013; 10(1): 38-42. [PMID: 26719842] 
[8] Kamal AF, Ismail HD, Mi'raj F, Hutagalung EU. Outcomes of stage IIB osteosarcoma treated by limb salvage surgery using extracorporeally irradiated (ECI) autograft. Med J Indones 2011; 20(2): 131-7.

[http://dx.doi.org/10.13181/mji.v20i2.441]

[9] Gebhardt MC, Hornicek FJ. Osteosarcoma. In: Orthopaedic Knowledge Update: Musculoskeletal Tumors Rosemont: American Academy of orthopaedic Surgeons. 2002; pp. 175-86.

[10] Bruland OS, Høifødt H, Saeter G, Smeland S, Fodstad O. Hematogenous micrometastases in osteosarcoma patients. Clin Cancer Res 2005; 11(13): 4666-73.

[http://dx.doi.org/10.1158/1078-0432.CCR-05-0165] [PMID: 16000559]

[11] Ritter J, Bielack SS. Osteosarcoma. Ann Oncol 2010; 21(Suppl. 7): vii320-5. [http://dx.doi.org/10.1093/annonc/mdq276] [PMID: 20943636]

[12] Jiang R, Gao ZL, Sun M, Zhang XY, Wang JC, Wu H. Zinc finger X-chromosomal protein promotes growth and tumorigenesis in human osteosarcoma cells. Pak J Med Sci 2013; 29(4): 997-1002. [http://dx.doi.org/10.12669/pjms.294.3498] [PMID: 24353675]

[13] Luu HH, Kang Q, Park JK, et al. An orthotopic model of human osteosarcoma growth and spontaneous pulmonary metastasis. Clin Exp Metastasis 2005; 22(4): 319-29

[http://dx.doi.org/10.1007/s10585-005-0365-9] [PMID: 16170668]

[14] Levings PP, McGarry SV, Currie TP, et al. Expression of an exogenous human Oct-4 promoter identifies tumor-initiating cells in osteosarcoma. Cancer Res 2009; 69(14): 5648-55. [http://dx.doi.org/10.1158/0008-5472.CAN-08-3580] [PMID: 19584295]

[15] Basu-Roy U, Basilico C, Mansukhani A. Perspectives on cancer stem cells in osteosarcoma. Cancer Lett 2013; 338(1): 158-67. [http://dx.doi.org/10.1016/j.canlet.2012.05.028] [PMID: 22659734]

[16] Gatti M, Wurth R, Vito G, et al. Canine osteosarcoma cell lines contain stem-like cancer cells: Biological and pharmacological characterization. Jpn J Vet Res 2016; 64(2): 101-12. [PMID: 27506084]

[17] Al-Hajj M, Wicha MS, Benito-Hernandez A, Morrison SJ, Clarke MF. Prospective identification of tumorigenic breast cancer cells. Proc Natl Acad Sci USA 2003; 100(7): 3983-8.

[http://dx.doi.org/10.1073/pnas.0530291100] [PMID: 12629218]

[18] Gibbs CP Jr, Levings PP, Ghivizzani SC. Evidence for the osteosarcoma stem cell. Curr Orthop Pract 2011; 22(4): 322-6. [http://dx.doi.org/10.1097/BCO.0b013e318221aee8] [PMID: 21755019]

[19] Gibbs CP, Kukekov VG, Reith JD, et al. Stem-like cells in bone sarcomas: Implications for tumorigenesis. Neoplasia 2005; 7(11): 967-76. [http://dx.doi.org/10.1593/neo.05394] [PMID: 16331882]

[20] Hurt EM, Farrar WL. Characterization of cancer stem cells.Cancer stem cells. Canbridge University 2010 ; p. 13.

[21] Reya T, Morrison SJ, Clarke MF, Weissman IL. Stem cells, cancer, and cancer stem cells. Nature 2001; 414(6859): 105-11. [http://dx.doi.org/10.1038/35102167] [PMID: 11689955]

[22] Gong C, Liao H, Wang J, et al. LY294002 induces G0/G1 cell cycle arrest and apoptosis of cancer stem-like cells from human osteosarcoma via down-regulation of PI3K activity. Asian Pac J Cancer Prev 2012; 13(7): 3103-7. [http://dx.doi.org/10.7314/APJCP.2012.13.7.3103] [PMID: 22994717]

[23] Liu B, Ma W, Jha RK, Gurung K. Cancer stem cells in osteosarcoma: Recent progress and perspective. Acta Oncol 2011; 50(8): 1142-50. [http://dx.doi.org/10.3109/0284186X.2011.584553] [PMID: 21718210]

[24] Li J, Zhong XY, Li ZY, et al. CD133 expression in osteosarcoma and derivation of CD133 cells. Mol Med Rep 2013; 7(2): $577-84$. [http://dx.doi.org/10.3892/mmr.2012.1231] [PMID: 23242469]

[25] Kelsey JL, Moore AS, Glickman LT. Epidemiologic studies of risk factors for cancer in pet dogs. Epidemiol Rev 1998; 20(2): 204-17. [http://dx.doi.org/10.1093/oxfordjournals.epirev.a017981] [PMID: 9919439]

[26] Fodstad O, Brøgger A, Bruland O, Solheim OP, Nesland JM, Pihl A. Characteristics of a cell line established from a patient with multiple osteosarcoma, appearing 13 years after treatment for bilateral retinoblastoma. Int J Cancer 1986; 38(1): 33-40. [http://dx.doi.org/10.1002/ijc.2910380107] [PMID: 3459716]

[27] Kadosawa T, Nozaki K, Sasaki N, Takeuchi A. Establishment and characterization of a new cell line from a canine osteosarcoma. J Vet Med Sci 1994; 56(6): 1167-9. [http://dx.doi.org/10.1292/jvms.56.1167] [PMID: 7696411]

[28] Pautke C, Schieker M, Tischer T, et al. Characterization of osteosarcoma cell lines MG-63, Saos-2 and U-2 OS in comparison to human osteoblasts. Anticancer Res 2004; 24(6): 3743-8. [PMID: 15736406]

[29] Séguin B, Zwerdling T, McCallan JL, et al. Development of a new canine osteosarcoma cell line. Vet Comp Oncol 2006; 4(4): 232-40. [http://dx.doi.org/10.1111/j.1476-5829.2006.00112.x] [PMID: 19754807]

[30] Hong SH, Kadosawa T, Mochizuki M, Matsunaga S, Nishimura R, Sasaki N. Establishment and characterization of two cell lines derived from canine spontaneous osteosarcoma. J Vet Med Sci 1998; 60(6): 757-60. 
[http://dx.doi.org/10.1292/jvms.60.757] [PMID: 9673952]

[31] McAllister RM, Gardner MB, Greene AE, Bradt C, Nichols WW, Landing BH. Cultivation in vitro of cells derived from a human osteosarcoma. Cancer 1971; 27(2): 397-402. [http://dx.doi.org/10.1002/1097-0142(197102)27:2<397::AID-CNCR2820270224>3.0.CO;2-X] [PMID: 5100401]

[32] Pontén J, Saksela E. Two established in vitro cell lines from human mesenchymal tumours. Int J Cancer 1967; 2(5): 434-47. [http://dx.doi.org/10.1002/ijc.2910020505] [PMID: 6081590]

[33] Fogh J, Trempe G. New human tumor cell lines.Human Tumor Cells in vitro. New York, NY, USA: Springer U.S. 1975; pp. 115-9. [http://dx.doi.org/10.1007/978-1-4757-1647-4_5]

[34] Billiau A, Edy VG, Heremans H, et al. Human interferon: mass production in a newly established cell line, MG-63. Antimicrob Agents Chemother 1977; 12(1): 11-5.

[http://dx.doi.org/10.1128/AAC.12.1.11] [PMID: 883813]

[35] Wilson H, Huelsmeyer M, Chun R, Young KM, Friedrichs K, Argyle DJ. Isolation and characterisation of cancer stem cells from canine osteosarcoma. Vet J 2008; 175(1): 69-75. [http://dx.doi.org/10.1016/j.tvjl.2007.07.025] [PMID: 17851099]

[36] Wang L, Park P, Lin CY. Characterization of stem cell attributes in human osteosarcoma cell lines. Cancer Biol Ther 2009; 8(6): 543-52. [http://dx.doi.org/10.4161/cbt.8.6.7695] [PMID: 19242128]

[37] Lou N, Wang Y, Sun D, Zhao J, Wang Y, Gao Z. Isolation of stem-like cells from human MG-63 osteosarcoma cells using limiting dilution in combination with vincristine selection. Indian J Biochem Biophys 2010; 47(6): 340-7. [PMID: 21355416]

[38] Aubele M, Werner M. Heterogeneity in breast cancer and the problem of relevance of findings. Anal Cell Pathol 1999; 19(2): 53-8. [http://dx.doi.org/10.1155/1999/960923] [PMID: 10746434]

[39] Guadamillas MC, Cerezo A, Del Pozo MA. Overcoming anoikis--pathways to anchorage-independent growth in cancer. J Cell Sci 2011; 124(Pt 19): 3189-97. [http://dx.doi.org/10.1242/jcs.072165] [PMID: 21940791]

[40] Chambers I, Colby D, Robertson M, et al. Functional expression cloning of Nanog, a pluripotency sustaining factor in embryonic stem cells. Cell 2003; 113(5): 643-55.

[http://dx.doi.org/10.1016/S0092-8674(03)00392-1] [PMID: 12787505]

[41] Karaoz E, Aksoy A, Ayhan S, Sariboyaci AE, Kaymaz F, Kasap M. Characterization of mesenchymal stem cells from rat bone marrow: Ultrastructural properties, differentiation potential and immunophenotypic markers. Histochem Cell Biol 2009; 132(5): 533-46. [http://dx.doi.org/10.1007/s00418-009-0629-6] [PMID: 19688349]

[42] Pan G, Thomson JA. Nanog and transcriptional networks in embryonic stem cell pluripotency. Cell Res 2007; 17(1): 42-9. [http://dx.doi.org/10.1038/sj.cr.7310125] [PMID: 17211451]

[43] Guth AM, Deogracias M, Dow SW. Comparison of cancer stem cell antigen expression by tumor cell lines and by tumor biopsies from dogs with melanoma and osteosarcoma. Vet Immunol Immunopathol 2014; 161(3-4): 132-40. [http://dx.doi.org/10.1016/j.vetimm.2014.07.006] [PMID: 25146881]

[44] Singh SK, Clarke ID, Terasaki M, et al. Identification of a cancer stem cell in human brain tumors. Cancer Res 2003; 63(18): 5821-8. [PMID: 14522905]

[45] Olmsted-Davis EA, Gugala Z, Camargo F, et al. Primitive adult hematopoietic stem cells can function as osteoblast precursors. Proc Natl Acad Sci USA 2003; 100(26): 15877-82 [http://dx.doi.org/10.1073/pnas.2632959100] [PMID: 14673088]

[46] Wang Q, Steigelman MB, Walker JA, et al. In vitro osteogenic differentiation of adipose stem cells after lentiviral transduction with green fluorescent protein. J Craniofac Surg 2009; 20(6): 2193-9. [http://dx.doi.org/10.1097/SCS.0b013e3181bf04af] [PMID: 19934675]

[47] Di Fiore R, Fanale D, Drago-Ferrante R, et al. Genetic and molecular characterization of the human osteosarcoma 3AB-OS cancer stem cell line: A possible model for studying osteosarcoma origin and stemness. J Cell Physiol 2013; 228(6): 1189-201. [http://dx.doi.org/10.1002/jcp.24272] [PMID: 23129384]

[48] Saini V, Hose CD, Monks A, et al. Identification of CBX3 and ABCA5 as putative biomarkers for tumor stem cells in osteosarcoma. PLoS One 2012; 7(8): e41401. [http://dx.doi.org/10.1371/journal.pone.0041401] [PMID: 22870217]

[49] He A, Qi W, Huang Y, et al. CD133 expression predicts lung metastasis and poor prognosis in osteosarcoma patients: A clinical and experimental study. Exp Ther Med 2012; 4(3): 435-41. [http://dx.doi.org/10.3892/etm.2012.603] [PMID: 23181114]

[50] Meyer FRL, Walter I. Establishment and characterization of new canine and feline osteosarcoma primary cell lines. Vet Sci 2016; 3(2): 1-15. [http://dx.doi.org/10.3390/vetsci3020009] [PMID: 29056719]

[51] Luk F, Yu Y, Dong HT, Walsh WR, Yang JL. New gene groups associated with dissimilar osteoblastic differentiation are linked to osteosarcomagenesis. Cancer Genomics Proteomics 2011; 8(2): 65-75. [PMID: 21471516] 
[52] Birmingham E, Niebur GL, McHugh PE, Shaw G, Barry FP, McNamara LM. Osteogenic differentiation of mesenchymal stem cells is regulated by osteocyte and osteoblast cells in a simplified bone niche. Eur Cell Mater 2012; 23: 13-27. [http://dx.doi.org/10.22203/eCM.v023a02] [PMID: 22241610]

[53] Siclari VA, Qin L. Targeting the osteosarcoma cancer stem cell. J Orthop Surg Res 2010; 5: 78. [http://dx.doi.org/10.1186/1749-799X-5-78] [PMID: 20979639]

[54] Liu B, Ma W, Jha RK, Gurung K. Cancer stem cells in osteosarcoma: Recent progress and perspective. Acta Oncol 2011; 50(8): 1142-50. [http://dx.doi.org/10.3109/0284186X.2011.584553] [PMID: 21718210]

(C) 2018 Kamal et al.

This is an open access article distributed under the terms of the Creative Commons Attribution 4.0 International Public License (CC-BY 4.0), a copy of which is available at: https://creativecommons.org/licenses/by/4.0/legalcode. This license permits unrestricted use, distribution, and reproduction in any medium, provided the original author and source are credited. 